

\title{
Editorial
}

\section{Do we need extended care paramedics?}

\author{
Malcolm Boyle PhD, Editor and Academic Lead in Paramedic Education ${ }^{1,2}$
}

\author{
Affiliations: \\ ${ }^{1}$ Australasian Journal of Paramedicine \\ ${ }^{2}$ Griffith University, School of Medicine, Queensland
}

The commentary by Reaburn and colleagues in this issue of the Australasian Journal of Paramedicine suggests another type of paramedic for rural areas of Australia - the rural paramedic - a combination of a paramedic and a physician assistant (1). This view is in line with other international studies, which have proposed and trialled extended care paramedics (2), emergency care practitioners (3), and community paramedics (4).

Australian university-based paramedic education programs were derived from the old state ambulance service-run vocational education and training sector paramedic programs. The university-based paramedic programs added a tertiary perspective to the upgraded paramedic education. What these tertiary education programs have not necessarily done is provide graduates with the education to meet the current and prospective ambulance workload and case type.

As an example, the total trauma workload for the state of Victoria in 2002 was about 15 percent, the remaining workload was made up of medical and other conditions (5). Of the total trauma workload nearly 50 percent of cases were falls (5), a condition that does not receive the educational time it should in Australian paramedic programs.

Therefore, should universities combine in an effort to analyse Australian ambulance data to establish what the caseload and case types are in a bid to guide the refinement of paramedic education programs in Australia, based on current and predicted ambulance caseload and case type?

Do we really need extended care paramedics until we can define what the knowledge and skill set should be for the basic paramedic? Then there is the knowledge level and skill set for the extended care paramedic, including the amount of clinical experience during the program, plus the time needed for knowledge and skill set maintenance. Now we have another knowledge and skill set for paramedics operating away from the urban area as described by Reaburn and colleagues (1), plus there are other models such as those described by O'Meara and colleagues (6).

The Health Workforce Australia (HWA) funded study and report into extended care paramedics in Australia failed to discuss the knowledge and skill set for the base level paramedic on which the extended care program would be built. The HWA study concentrated on five sites around Australia evaluating an extended care program and the potential effectiveness of the extended care paramedic in managing the patients within their scope of practice (7). One noticeable point was the different levels of extended care provided at the sites investigated.

This shows that there is a requirement for defined levels of care that need to be specified before a rigorous course accreditation process, leading to registration. There should be a minimum standard for each level of paramedic in the registration process, similar to that in the United States of America (8). Even though university paramedic courses are currently accredited by the Council of Ambulance Authorities, there is still a variation in the standard of paramedic courses and paramedic graduates. Currently paramedicine is not a registered health profession in Australia, although this is expected to change in late 2018. 
So does Australia really need extended care paramedics or do paramedics need to be educated to better serve the community they work in? Is it time to move from the generalist paramedic to a more specialised paramedic? It would make more sense to educate graduate paramedics to a base level that is determined by a more scientific approach, based on current and projected ambulance caseload and case type. Following the generalist training, further educate the graduate paramedic to serve the community they will be working in, be it urban, rural or remote. This concept may need some further thought and discussion, but it may be a better way to meet the needs of different communities in the future.

Dr Mal Boyle

Editor

Australasian Journal of Paramedicine

\section{References}

1. Reaburn G, Zolcinski R, Fyfe S. Rural paramedic practitioner - a future model of care. Australasian Journal of Paramedicine 2017;14(1).

2. Hoyle S, Swain AH, Fake P, Larsen PD. Introduction of an extended care paramedic model in New Zealand. Emerg Med Australas 2012;24:652-6.

3. Mason S, O'Keeffe C, Knowles $\mathrm{E}$, et al. A pragmatic quasi-experimental multi-site community intervention trial evaluating the impact of emergency care practitioners in different UK health settings on patient pathways (NEECaP Trial). Emerg Med J 2012;29:47-53.

4. Nolan M, Hillier T, D'Angelo C. Community paramedicine in Canada. Ottawa, Ontario, Canada: Emergency Medical Services Chiefs of Canada; 2011.

5. Boyle MJ, Smith E, Archer FL. Trauma incidents attended by emergency medical services in Victoria, Australia. Prehosp Disaster Med 2008;23:9.

6. O'Meara P, Tourle V, Stirling C, Walker J, Pedler D. Extending the paramedic role in rural Australia: A story of flexibility and innovation. Rural Remote Health 2012;12.

7. Thompson C, Williams K, Morris D, et al. HWA Expanded Scopes of Practice Program Evaluation: Extending the Role of Paramedics Sub-Project Final Report. Wollongong, NSW, Australia.: Centre for Health Service Development, Australian Health Services Research Institute, University of Wollongong; 2014.

8. National Registry of Emergency Medical Technicians. Candidates. Ohio, USA. Available at: www.nremt.org/rwd/public/ document/candidates [Accessed 28 January 2017]. 